\title{
DIAGNOSTIC ACCURACY OF DIFFUSION WEIGHTED MRI IN DIFFERENTIATING WHO GRADE-1 FROM HIGH-GRADE MENINGIOMAS
}

\author{
Rani Ann Joseph ${ }^{1}$, Anusha Lingaiah Pujar², Manoj Thankappan Pillai ${ }^{3}$
}

${ }^{1}$ Senior Resident, Department of Radiodiagnosis, Government Medical College, Thrissur.

${ }^{2}$ Senior Resident, Department of Radiodiagnosis, District Hospital, Ballari.

${ }^{3}$ Associate Professor, Department of Radiodiagnosis, Government Medical College, Kollam.

\section{ABSTRACT}

\section{BACKGROUND}

The aim is to study the diagnostic accuracy of diffusion weighted magnetic resonance imaging in differentiating WHO Grade-1, from high-grade meningiomas and comparing with histopathology as the gold standard.

\section{MATERIALS AND METHODS}

100 patients with intracranial meningiomas referred to the Department of Radiodiagnosis for imaging were included in the study after applying inclusion and exclusion criteria. MR imaging of the head with diffusion weighted imaging was done. ADC was calculated with B value of 0 - 1000. Cut-off was obtained after drawing ROC for ADC values.

\section{RESULTS}

Using ADC value as the diagnostic test, present study shows a sensitivity of $90.48 \%$ and specificity of $98.73 \%$ (p $<0.0001$ ) for differentiating Grade-1 and high-grade meningiomas.

\section{CONCLUSION}

Diffusion weighted imaging in the tumour can reliably differentiate between WHO Grade-1 and high-grade meningiomas.

\section{KEYWORDS}

MRI, ADC, Differentiation of Grade-1 and High-Grade Meningiomas, Diffusion Weighted Imaging.

HOW TO CITE THIS ARTICLE: Joseph RA, Pujar AL, Pillai MT. Diagnostic accuracy of diffusion weighted MRI in differentiating who grade-1 from high-grade meningiomas. J. Evolution Med. Dent. Sci. 2017;6(38):3097-3102, D0I: 10.14260/Jemds/2017/668

\section{BACKGROUND}

Meningioma is the most common primary non-glial benign intracranial neoplasm and arise from the arachnoid cap cells. Meningiomas are the most common of all brain tumours, accounting for one-quarter to one-third of all primary intracranial neoplasms. ${ }^{1}$

Although most meningiomas are benign, they show a broad spectrum of clinical characteristics, and histologically distinct subsets are associated with high risk of recurrence, even after seemingly complete resection. In rare instances, meningiomas are invasive and malignant. The WHO classification helps to better predict the divergent clinical characteristics of meningioma with a histological grading system based on statistically significant clinicopathological correlations. There are three types of meningiomas according to malignancy grades: benign (WHO Grade I), atypical (WHO Grade II) and anaplastic (malignant; WHO Grade III) meningiomas. ${ }^{2}$

Magnetic Resonance (MR) imaging is the imaging modality most commonly used to evaluate intracranial meningiomas. In addition to conventional MR imaging techniques, a variety of advanced techniques are also commonly used in clinical practice.

Financial or Other, Competing Interest: None.

Submission 06-04-2017, Peer Review 30-04-2017,

Acceptance 06-05-2017, Published 11-05-2017.

Corresponding Author:

Rani Ann Joseph,

\#28/13, Arch Road

Kuttanellur P.O.,

Thrissur-680014, Kerala.

E-mail: annranij@gmail.com

DOI: $10.14260 /$ jemds $/ 2017 / 668$

\section{(c) $(1)$}

These advanced MR imaging techniques help in demonstrating more than the anatomic information provided by the conventional magnetic resonance imaging sequences. Diffusion Weighted Imaging (DWI) is used to assess the biological and histological characteristics of brain tumours and may distinguish brain tumour grades, presumably due to differences in tumour cellularity and biochemical properties of extra-cellular space. Grade- 2 and Grade- 3 meningiomas are seen to have lower apparent diffusion coefficient than Grade1 meningiomas, considered to be a consequence of high cellularity and restricted motion in the extracellular space. ${ }^{3}$

The present study was carried out to assess the accuracy of measurement of ADC values by diffusion weighted MRI in differentiating Grade- 1 from high-grade meningiomas, while taking histopathological findings as the gold standard.

\section{MATERIALS AND METHODS}

This cross-sectional study was carried out in the Department of Radiodiagnosis, Government Medical College, Thiruvananthapuram for eighteen months from May 2014 to October 2015; 100 patients referred to the Department of Radiodiagnosis for MRI brain for the evaluation of suspected meningiomas diagnosed by CT brain and being planned for an incisional or excisional biopsy were included in the study.

Patients with pacemakers, cochlear implants, ferromagnetic foreign bodies or metallic implants, patients not willing to participate in the study and those patients with recurrent or residual meningioma following surgery were excluded from the study.

Name, age and relevant details of the patient was recorded on a proforma. Patients were informed that data collected would be used in a study and that issues related to confidentiality and anonymity would be taken due care of. 
After obtaining informed consent, MR examinations were performed on a 1.5T Siemens Magnetom system. Axial T1weighted spin-echo, axial fluid attenuated inversion recovery (FLAIR) sequences, sagittal, axial and coronal T2WI and diffusion weighted axial images were performed.

\begin{tabular}{|c|c|c|c|c|}
\hline Parameters & T1WI & T2WI & DWI & FLAIR \\
\hline TR (ms) & 409 & 4000 & 3000 & 9000 \\
\hline TE (ms) & 8.4 & 94 & 89 & 89 \\
\hline No. of Excitations & 1 & 3 & 4 & 1 \\
\hline FOV (cm x cm) & $23 \times 23$ & $23 \times 23$ & $23 \times 23$ & $23 \times 23$ \\
\hline Slice Thickness & 5 & 5 & 5 & 5 \\
\hline (mm) & & & & 30 \\
\hline Interslice gap (\%) & 30 & 30 & 30 & 30 \\
\hline \multicolumn{7}{|l|}{ Table 1. Parameters used in MR Imaging of Brain } \\
\hline
\end{tabular}

From the diffusion weighted images, ADC values were calculated for each image.

$\mathrm{ADC}$ was calculated by the formula,

$$
D=\frac{1}{\left(b_{1}-b_{2}\right)} \ln \left[\frac{S\left(T E, b_{2}\right)}{S\left(T E, b_{1}\right)}\right]
$$

Where $\mathrm{D}$ is the ADC, $\mathrm{b} 1$ and $\mathrm{b} 2$ the two $\mathrm{b}$ values, $\mathrm{S}$ (TE, b1) and $S$ (TE, b2) the signal intensities in the respective diffusion weighted images.

After undergoing incisional or excisional biopsy in the Department of Neurosurgery, the histopathology report of the specimens was collected from the Department of Pathology.

Statistical analysis was performed with commercially available software (IBM SPSS statistics 22; MedCalc 15.10). The ADC values were then correlated with the results of histopathological examination. The means of the ADC values of Grade- 1 and high-grade meningiomas were expressed as mean \pm standard error of the mean. The differences between the means of Grade- 1 and high-grade meningiomas were compared using an independent samples t-test. With histopathology as gold standard, the receiver operating characteristic curves (ROC) and suitable cut-off values were generated. Using the cut-off value, statistical parameters like sensitivity, specificity, positive predictive value, negative predictive value, positive likelihood ratio and negative likelihood ratio were calculated.

\section{RESULTS}

Magnetic resonance imaging with diffusion weighted imaging and ADC mapping was done for the patients to image meningiomas. The observations are as follows. Over a period of 18 months, total of 100 patients were included in the study. In these patients, post-operative histopathological report was obtained; 21 (21\%) of the 100 meningiomas studied were WHO Grade-2 meningiomas and 79 (79\%) were WHO Grade-1 meningiomas. None of the meningiomas studied were Grade-3 meningiomas.

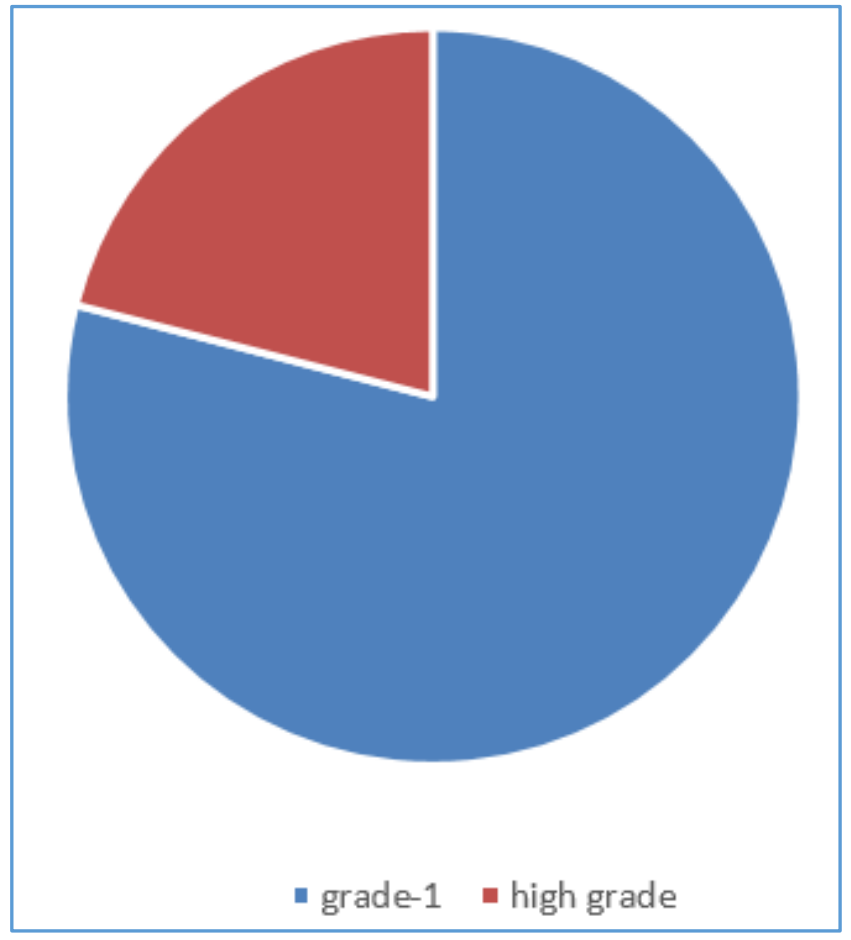

Figure 1. Distribution of Grade-1 and High-Grade Meningiomas

\section{Age Distribution of Patients}

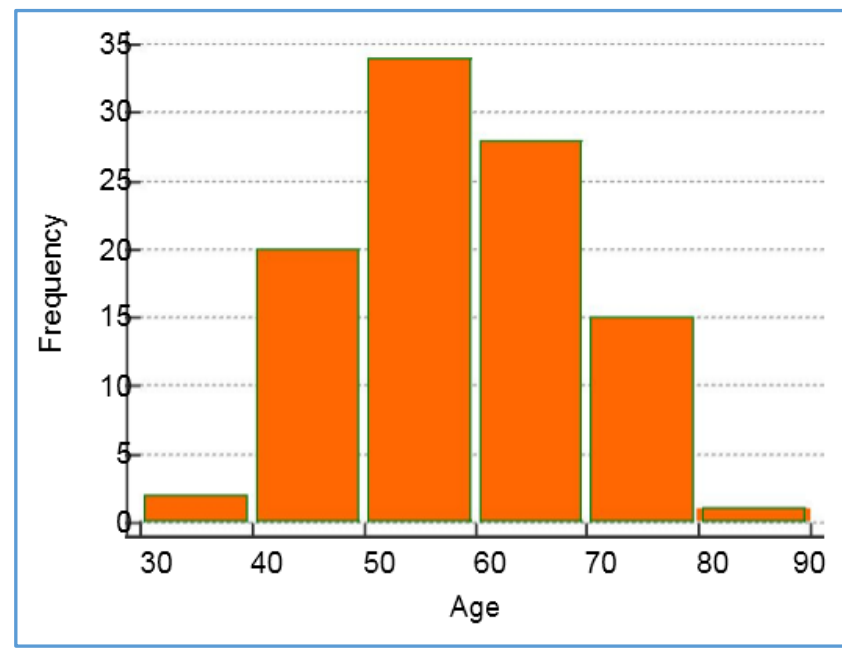

Figure 2- Histogram showing Age Distribution of Patients Studied

Of the 100 patients studied, 21 patients had high-grade meningiomas and 79 patients had Grade- 1 meningiomas. The commonest age group of meningiomas in the study was 51 60 years (33 patients) followed by 61 - 70 years (29 patients). The oldest patient was 84 years and the youngest patient was 36 years of age. Most of the atypical meningiomas were found in the age group of 51 - 60 years; 13 (61\%) of the atypical meningiomas were noted in 51 - 60 years. 


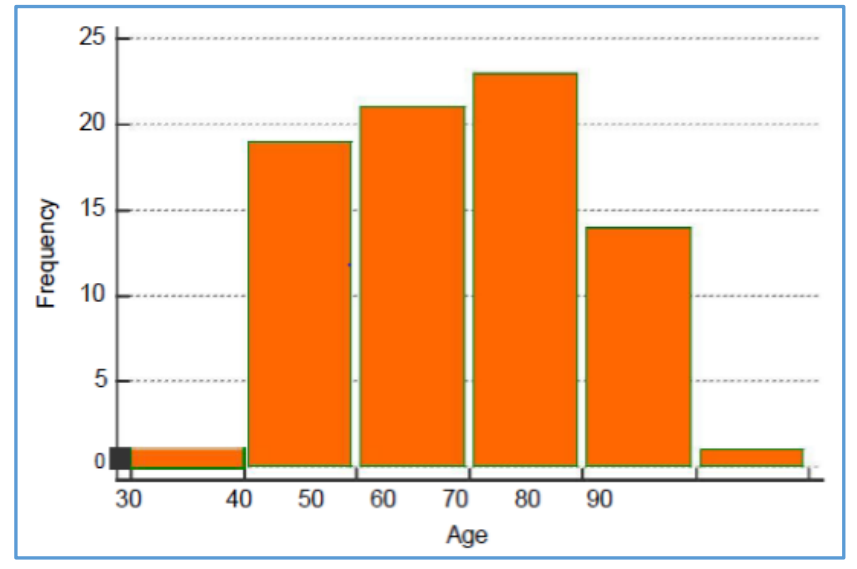

Figure 3. Age Distribution of Grade-1 Meningiomas

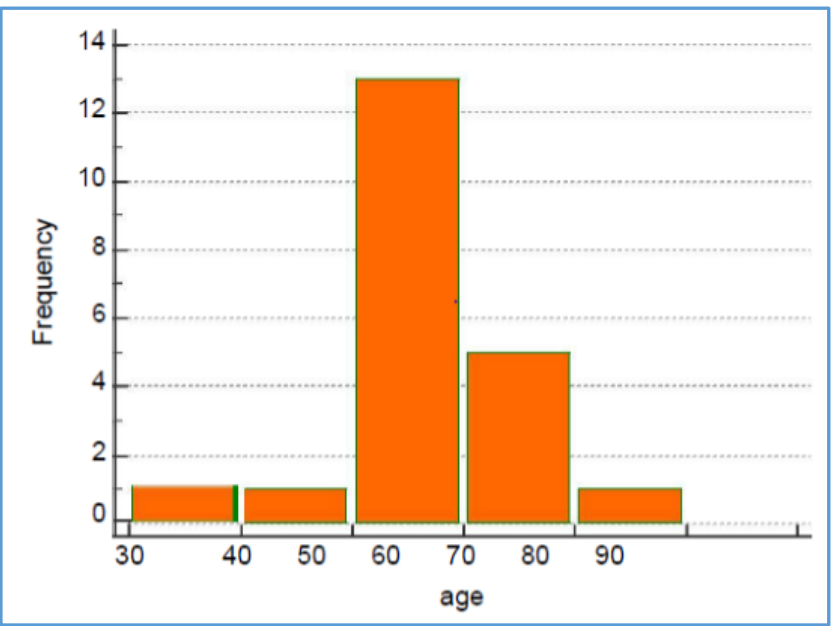

Figure 4. Age Distribution of High-Grade Meningiomas

\section{Sex Distribution of Patients in the Study}

Of the 100 patients in the study, 76 were females (76\%) and 24 were males $(24 \%)$.

\section{Sex distribution}

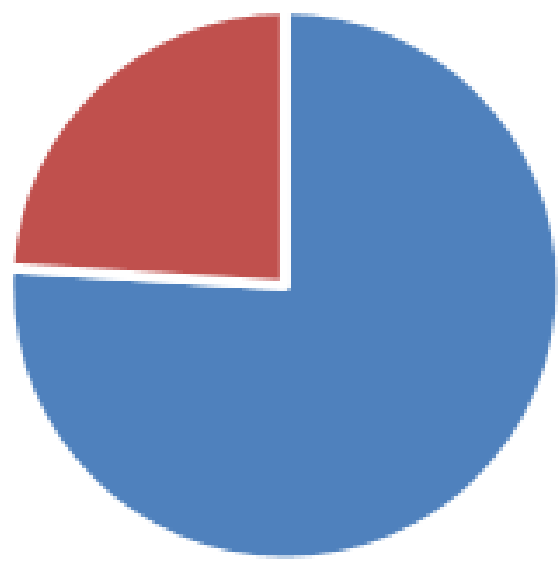

\section{- females " males}

Figure 5. Sex Distribution of Patients in the Study

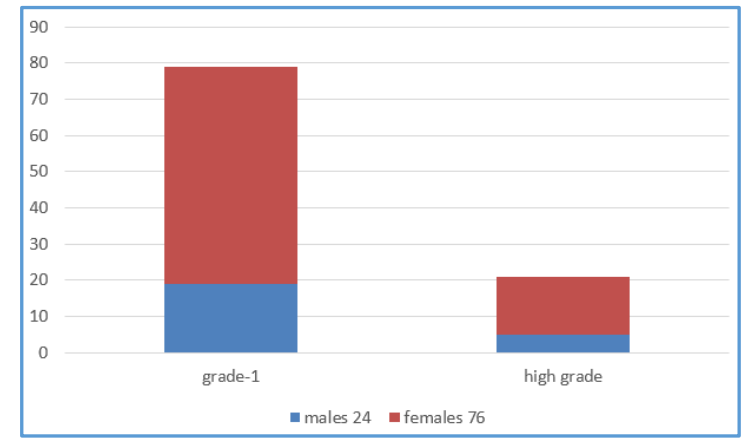

Figure 6. Sex Wise Distribution of Grade-1 and High-Grade Meningiomas

Of the 76 females studied, 16 (21\%) of them had highgrade meningiomas and $60(79 \%)$ patients have Grade-1 meningiomas. Of the 24 males studied, 5 (20.8\%) of them had high-grade meningiomas and 19 patients (79\%) had Grade-1 meningiomas.

\section{Evaluation of ADC Values of Meningiomas}

Diffusion weighted axial images of the brain were obtained at $a$ ' $b$ ' value of 1000. ADC maps were created for ' $b$ ' value of 1000.

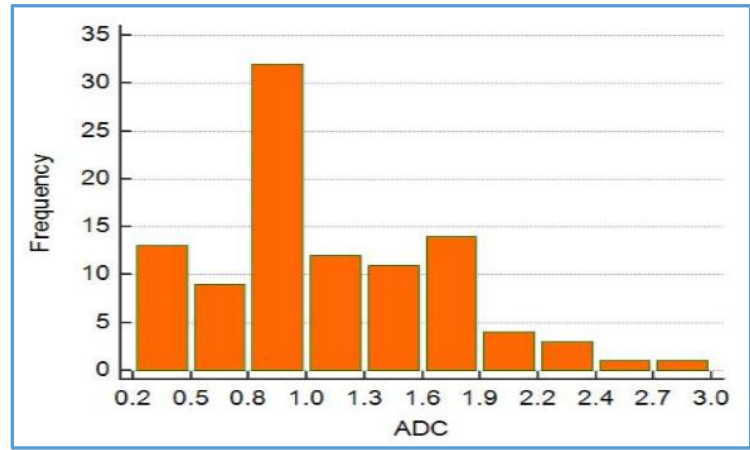

Figure 7. Distribution of ADC Values of Meningiomas

\begin{tabular}{|c|c|c|c|c|c|}
\hline \multirow{2}{*}{ Outcome } & \multirow{2}{*}{$\mathbf{N}$} & \multicolumn{2}{|c|}{ ADC } & \multirow{2}{*}{ T } & \multirow{2}{*}{ P } \\
\cline { 3 - 4 } & & Mean & SD & & \\
\hline Grade-1 & 79 & 1.31 & 0.51 & 7.546 & $<0.001$ \\
\hline High Grade & 21 & 0.46 & 0.16 & & \\
\hline
\end{tabular}

Table 2. Statistical Analysis of ADC Values of Meningiomas

On DWI, the ADC values of meningiomas ranged from $0.27 \times 10^{-3} \mathrm{~mm}^{2} / \mathrm{s}$ to $2.8 \times 10^{-3} \mathrm{~mm}^{2} / \mathrm{s}$

The mean and SD of absolute intratumoral ADC in Grade1 meningioma was $1.31 \pm 0.51 \times 10^{-3} \mathrm{~mm}^{2} / \mathrm{s}$, and in highgrade meningiomas the mean ADC of $0.46 \pm 00.16 \times 10^{-3}$ $\mathrm{mm}^{2} / \mathrm{s}$ was significantly lower $(\mathrm{p}<0.0001)$.

Receiver Operator Curve Analysis of Intratumoral ADC Values.

\begin{tabular}{|c|c|c|c|c|c|c|}
\hline Criterion & Sensitivity & Specificity & +LR & -LR & +PV & -PV \\
\hline$<0.27$ & 0.00 & 100.00 & & 1.00 & & 86.4 \\
\hline$\leq 0.47$ & 61.90 & 100.00 & & 0.38 & 100.0 & 94.3 \\
\hline$\leq 0.5$ & 71.43 & 98.73 & 56.43 & 0.29 & 89.9 & 95.6 \\
\hline$\leq 0.6$ & 90.48 & 98.73 & 71.48 & 0.096 & 91.8 & 98.5 \\
\hline$\leq 0.85$ & 90.48 & 83.54 & 5.50 & 0.11 & 46.4 & 98.2 \\
\hline$\leq 0.86$ & 95.24 & 83.54 & 5.79 & 0.057 & 47.7 & 99.1 \\
\hline$\leq 0.87$ & 100.00 & 78.48 & 4.65 & 0.00 & 42.2 & 100.0 \\
\hline$\leq 2.8$ & 100.00 & 0.00 & 1.00 & & 13.6 & \\
\hline
\end{tabular}

Table 3. Criterion Values and Coordinates of the ROC Curve 


\begin{tabular}{|c|c|}
\hline Area under the ROC curve (AUC) & 0.980 \\
\hline Standard Error & 0.0128 \\
\hline 95\% Confidence Interval & 0.930 to 0.998 \\
\hline Z statistic & 37.578 \\
\hline Significance Level P (Area = 0.5) & $<0.001$ \\
\hline Youden Index J & 0.8921 \\
\hline Associated Criterion & $\leq 0.6$ \\
\hline \multicolumn{2}{|c|}{ Table 4. Parameters obtained } \\
in ROC Analysis of Intratumoral ADC \\
\hline
\end{tabular}

From the graph, a cut-off value of $0.6 \times 10^{-3} \mathrm{~mm}^{2} / \mathrm{s}$ was derived. This cut-off has a sensitivity of $90.48 \%$ and specificity of $98.73 \%$. Positive likelihood ratio with this cutoff is 71.48 and negative likelihood ratio is 0.096 .

\begin{tabular}{|c|c|c|}
\hline ADC & High Grade & Grade-1 \\
\hline$\leq 0.6$ & 19 & 1 \\
\hline$>0.6$ & 2 & 78 \\
\hline Total & $\mathbf{2 1}$ & $\mathbf{7 9}$ \\
\hline Table 5. $2 \times 2$ Table with 0.6 as Cut-Off for ADC \\
\hline
\end{tabular}

\begin{tabular}{|c|c|c|}
\hline Statistical Index & & $\mathbf{9 5 \%}$ CI \\
\hline Sensitivity & $90.48 \%$ & $69.6-98.9$ \\
\hline Specificity & $98.73 \%$ & $93.1-100$ \\
\hline Positive predictive value & $91.8 \%$ & $63.9-99.7$ \\
\hline Negative predictive value & $98.5 \%$ & $93.2-99.9$ \\
\hline Positive likelihood ratio & 71.48 & $10.1-503.6$ \\
\hline Negative likelihood ratio & 0.096 & $0.03-0.4$ \\
\hline Table 6. Statistical Indices with 0.6 as cut-off for $\boldsymbol{A D C}$ \\
\hline
\end{tabular}

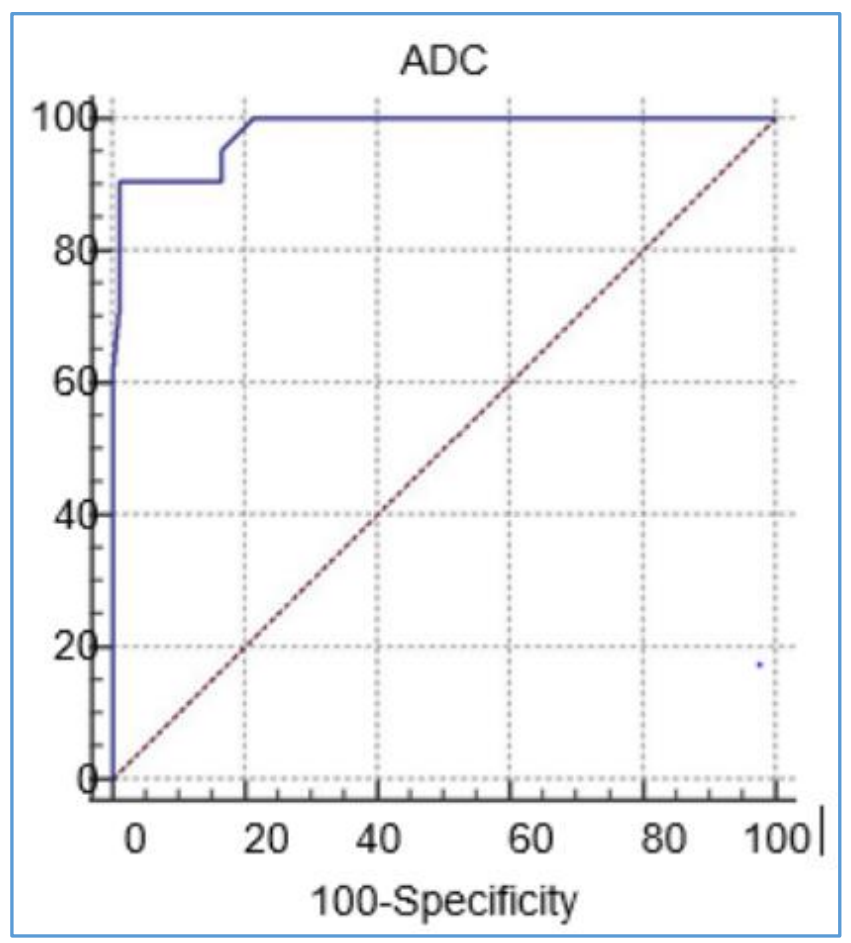

Figure 8. ROC Curve for Predicting cut-off for ADC

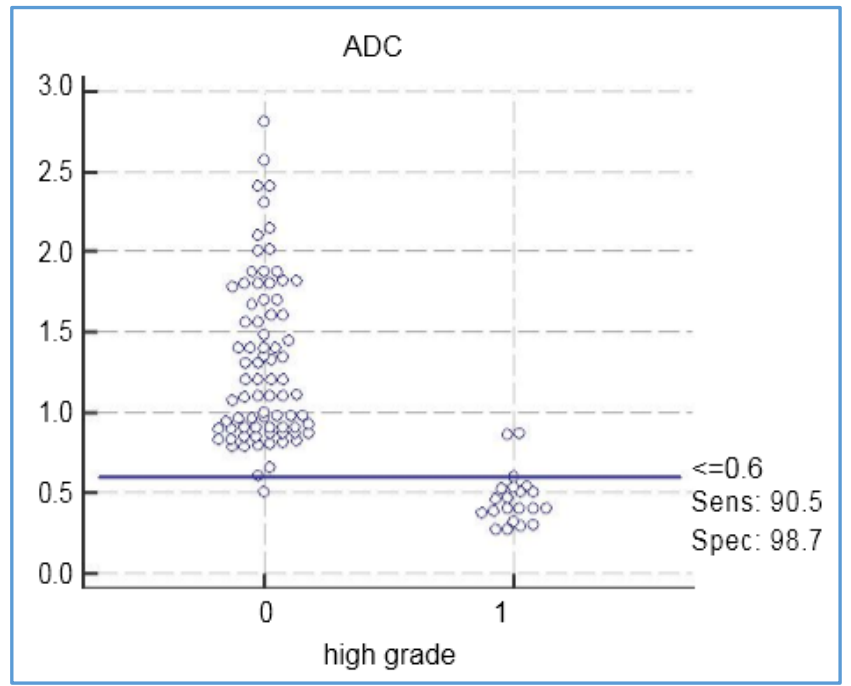

Figure 9. Scatter Diagram showing

Distribution of Intratumoral ADC

Nagar VA et al in their study "Diffusion-Weighted MR Imaging: Diagnosing atypical or malignant meningiomas and detecting tumour dedifferentiation." Published in 2014, an ADC cut-off of $0.8 \times 10^{-3} \mathrm{~mm}^{2} / \mathrm{s}$ was derived to differentiate benign from atypical/malignant meningiomas. ${ }^{4}$ With this cutoff, $2 \times 2$ table was constructed to assess the diagnostic power of ADC 0 - 1000 with literature cut-off value.

\begin{tabular}{|c|c|c|}
\hline ADC & High Grade & Grade-1 \\
\hline$<0.8$ & 8 & 17 \\
\hline$>0.8$ & 13 & 62 \\
\hline Total & $\mathbf{2 1}$ & $\mathbf{7 9}$ \\
\hline Table 7. 2 × 2 Table in assessing Diagnostic \\
Power of ADC using Literature Cut-Off Value \\
\hline
\end{tabular}

\section{The Calculated Parameters are as follows}

\begin{tabular}{|c|c|c|}
\hline Statistical Index & & $\mathbf{9 5 \%}$ CI \\
\hline Sensitivity & $38.10 \%$ & $18.11-61.56$ \\
\hline Specificity & $78.48 \%$ & $67.80-86.94$ \\
\hline Positive Predictive Value & $21.79 \%$ & $7.67-43.34$ \\
\hline Negative Predictive Value & $88.96 \%$ & $79.69-94.98$ \\
\hline \multicolumn{3}{|c|}{ Table 8. Statistical Parameters with } \\
Literature Cut-Off for ADC
\end{tabular}

\begin{tabular}{|c|c|c|c|c|}
\hline & Sensitivity & Specificity & PPV & NPV \\
\hline & $\%$ & $\%$ & $\%$ & $\%$ \\
\hline $\begin{array}{c}\text { Literature cut-off } \\
\text { (Nagar VA et al) }\end{array}$ & 96 & 82.6 & 85.7 & 95 \\
\hline $\begin{array}{c}\text { Applying in } \\
\text { Present Study }\end{array}$ & 38.1 & 78.48 & 21.79 & 88.96 \\
\hline \multicolumn{4}{|c|}{ Table 9. Comparison of ADC Cut-Off } \\
obtained in the Study and in Literature \\
\hline \multicolumn{6}{|l}{} \\
\hline
\end{tabular}




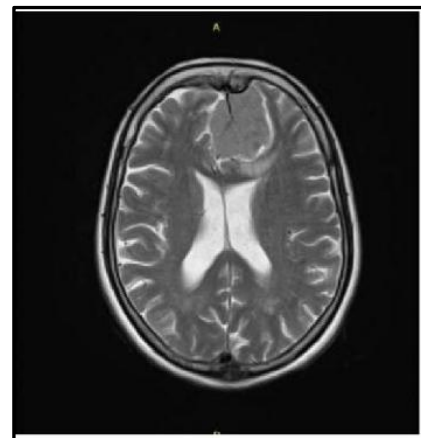

(A)

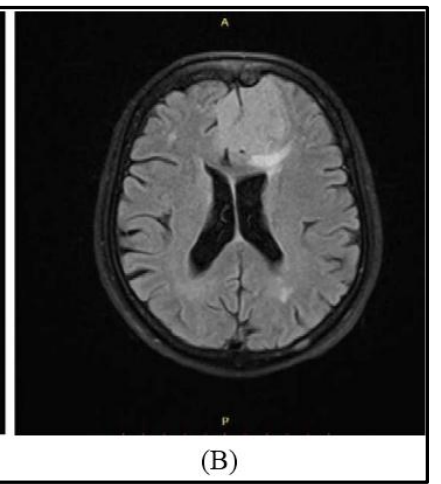

(B)

Figure 10(A). T2WI of HPR-WHO Grade-1 Meningioma of the Falx Cerebri.

(B) FLAIR Image of HPR-WHO Grade-1 Meningioma of Falx Cerebri.

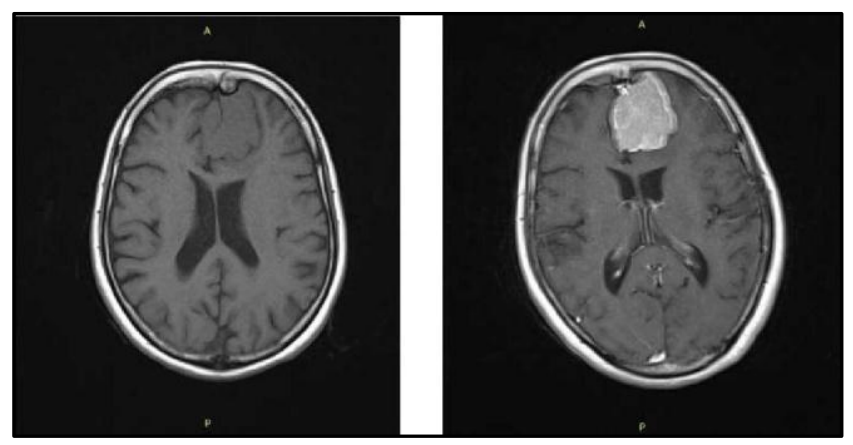

Figure 11(A). T1WI of HPR-WHO Grade-1 Meningioma of the Falx.

(B) Post-Contrast Image of WHO Grade-1 Meningioma of the Falx.

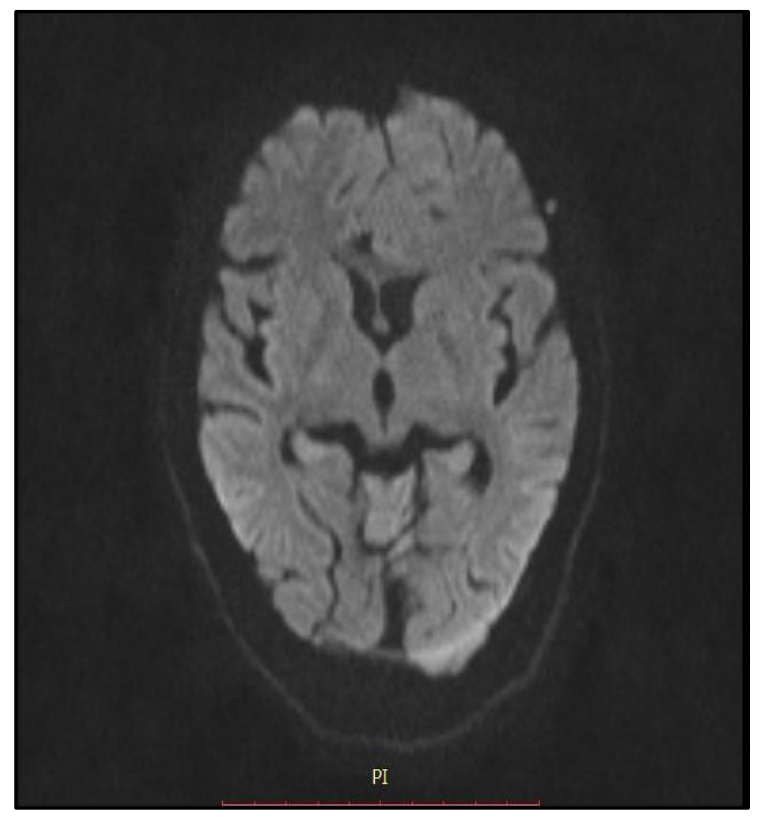

Figure 12. Diffusion Weighted Image of HPR-WHO Grade-1 Meningioma of the Falx

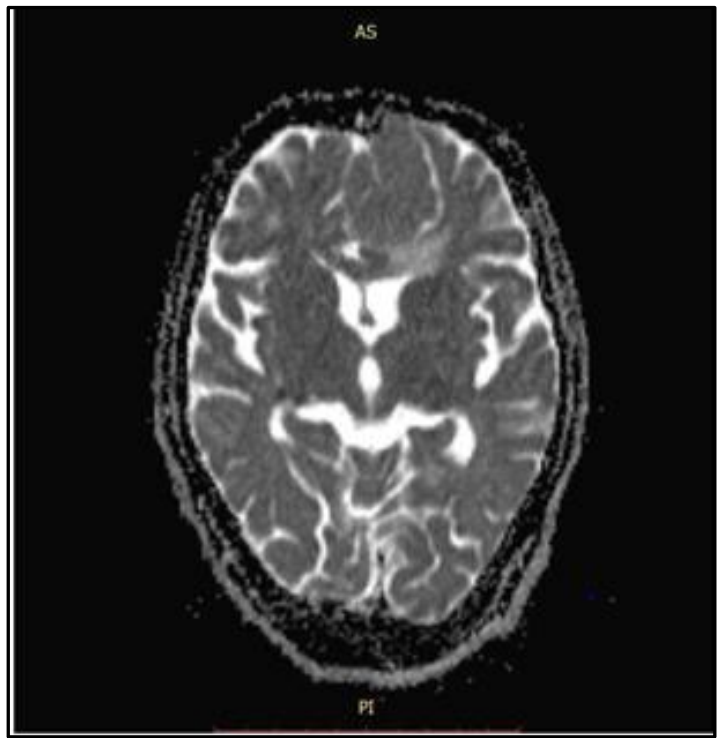

Figure 13. ADC Map of HPR-WHO Grade-1 meningioma of the Falx

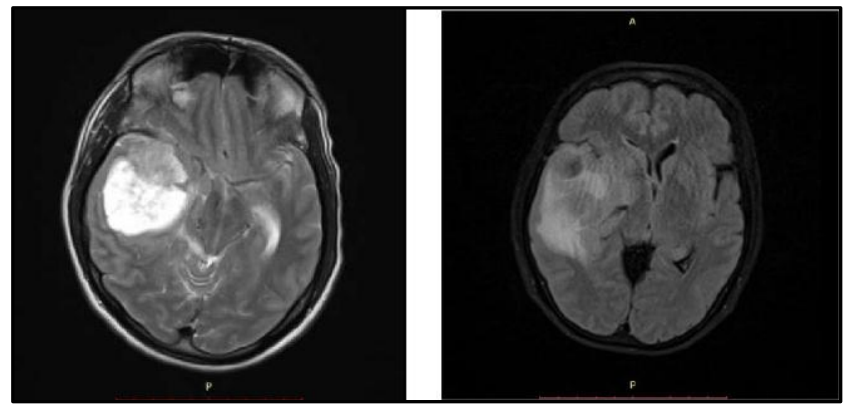

Figure 14 (A). T2WI of Grade-2 Meningioma of Right Temporal Region.

(B) FLAIR Image of Grade-2 Meningioma of Right Temporal Region.

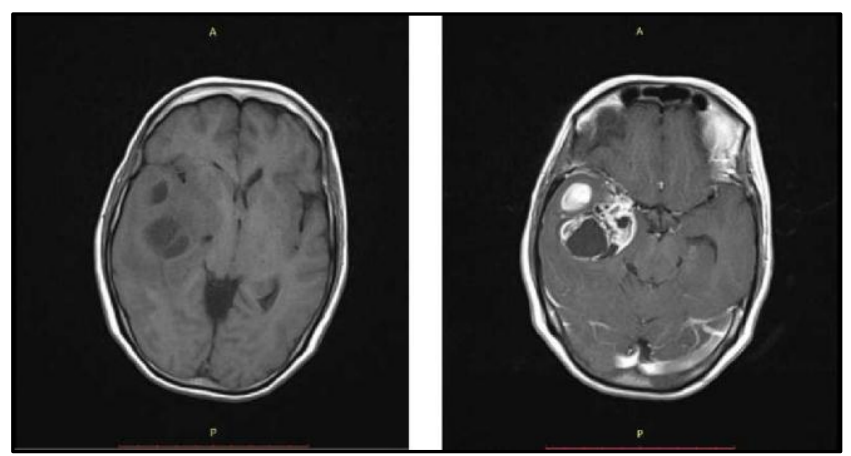

Figure 15(A). T1WI of Grade-2 Meningioma of Right Temporal Region.

(B) Post Contrast Image of Grade-2 Meningioma of the Right Temporal Region. 


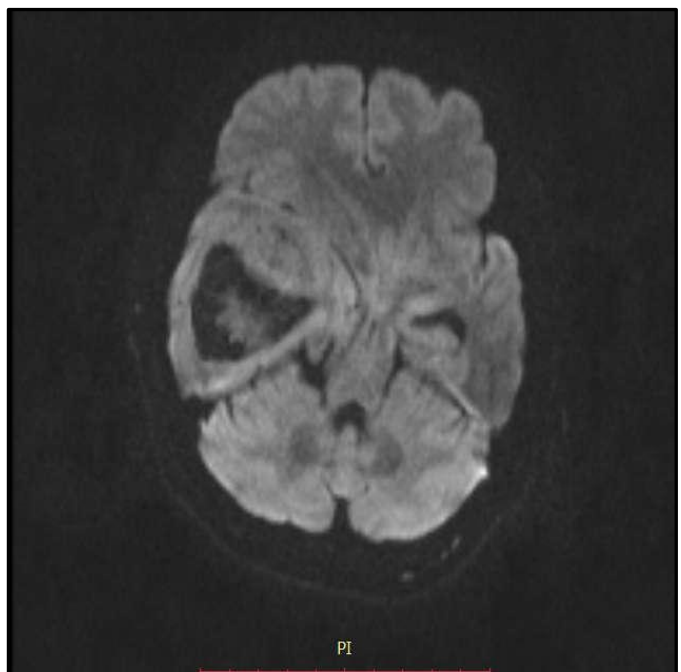

Figure 16. Diffusion Weighted Image of Grade-2 Meningioma of Right Temporal Region

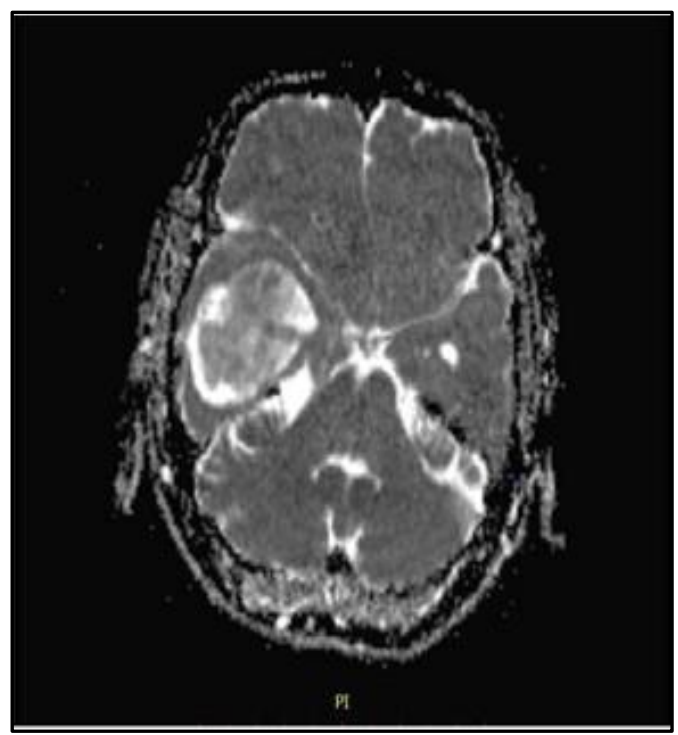

Figure 17. ADC Map of Grade-2 Meningioma of the Right Temporal Region

\section{DISCUSSION}

\section{Age and Sex Distribution}

Of the 100 patients studied, 21 patients had high-grade meningiomas and 79 patients had grade- 1 meningiomas. The commonest age group of meningiomas in the study was 51 60 years (33 patients) followed by $61-70$ years (29 patients). The oldest patient was 84 years and the youngest patient was 36 years of age. Most of the atypical meningiomas were found in the age group of 51 - 60 years; 13 (61\%) of the atypical meningiomas were noted in 51 - 60 years.

Of the 100 patients in the study, 76 were females (76\%) and 24 were males (24\%). Of the 76 females studied, 16 (21\%) of them had high-grade meningiomas and 60 (79\%) patients had Grade- 1 meningiomas. Of the 24 males studied, 5 $(20.8 \%)$ of them had high-grade meningiomas and 19 patients $(79 \%)$ had Grade-1 meningiomas.

\section{Histopathological Results}

Over a period of 18 months, total of 100 patients were included in the study. In these patients, post-operative histopathological report was obtained; 21 (21\%) of the 100 meningiomas studied were WHO Grade-2 meningiomas, and 79 (79\%) were WHO Grade-1 meningiomas. None of the meningiomas studied were Grade-3 meningiomas.

\section{ADC Values}

On DWI, the ADC values of meningiomas ranged from $0.27 \mathrm{x}$ $10^{-3} \mathrm{~mm}^{2} / \mathrm{s}$ to $2.8 \times 10^{-3} \mathrm{~mm}^{2} / \mathrm{s}$. The mean and SD of absolute intratumoral ADC in Grade- 1 meningioma was $1.31 \pm 0.51 \mathrm{x}$ $10^{-3} \mathrm{~mm}^{2} / \mathrm{s}$, and in high-grade meningiomas the mean ADC of $0.46 \pm 00.16 \times 10^{-3} \mathrm{~mm}^{2} / \mathrm{s}$ was significantly lower $(\mathrm{p}<$ 0.0001)

By ROC analysis, a cut-off value of $0.6 \times 10^{-3} \mathrm{~mm}^{2} / \mathrm{s}$ was derived. This cut-off has a sensitivity of $90.48 \%$ and specificity of $98.73 \%$. Positive likelihood ratio with this cutoff is 71.48 and negative likelihood ratio is 0.096 ( $p$ value < $0.001)$.

Nagar VA et al in their study of "Diffusion-Weighted MR Imaging: Diagnosing atypical or malignant meningiomas and detecting tumour dedifferentiation." Published in 2014, an ADC cut-off of $0.8 \times 10^{-3} \mathrm{~mm}^{2} / \mathrm{s}$ was derived to differentiate benign from atypical/malignant meningiomas.

\section{Limitations of the Study}

1. The study sample might not be a true representative of the real world due to "sampling errors" and spectrum bias.

2. Inoperable cases of meningiomas were omitted from the study.

3. None of the meningiomas studied were Grade-3 meningiomas. Hence, the findings may not apply to Grade-3 meningiomas.

\section{CONCLUSION}

ADC values can be reliably used to differentiate Grade- 1 from high-grade meningiomas. Thus, preoperative characterisation of meningiomas is possible for planning further management.

\section{ACKNOWLEDGEMENT}

We are thankful to the Department of Radiodiagnosis, Government Medical College, Thiruvananthapuram for all the help in carrying out this study.

\section{REFERENCES}

[1] Osborn AG. Tumors of the meninges. In: Ashley R, Renlund MA. Osborn's brain: imaging, anatomy and pathology. Amirsys Publishing, Inc 2013:584-97.

[2] Riemenschneider MJ, Perry A, Reifenberger G. Histological classification and molecular genetics of meningiomas. Lancet Neurol 2006;5(12):1045-54.

[3] Tantawy HI, Mohamad FF, Ismae AM. The role of advanced MRI techniques in differentiating typical, from atypical and malignant meningiomas. The Egyptian journal of radiology and nuclear medicine 2010;41(3):411-9.

[4] Nagar VA, Ye JR, Ng WH, et al. Diffusion-weighted MR imaging: diagnosing atypical or malignant meningiomas and detecting tumor dedifferentiation. AJNR Am J Neuroradiol 2008;29(6):1147-52. 